\title{
Formulation of Alkaloid Loaded Phytosomes from Tinospora cordifolia and ex-vivo Intestinal Permeability Study
}

\author{
Aishwarya Laxman Thakur, Kalpana Sabanna Patil* \\ Department of Pharmacognosy and Phytochemistry, KLE College of Pharmacy-Belagavi, KLE Academy of Higher Education and \\ Research (KAHER), Belagavi, Karnataka, INDIA.
}

\begin{abstract}
Background: Phytosomes are newly introduced novel dosage form for improving the bioavailability and therapeutic effect of the herbal drug. The present study aimed to prepare and evaluate the alkaloid loaded phytosome from Tinospora cordifolia. Materials and Methods: Extracts were screened for total content of phenols, flavonoids and alkaloids. The prepared extract was further used for fractionation and dichloromethane fraction (F3) was used to prepare phytosomes. Phytosome was prepared by using thin film hydration method with different ratio of soya lecithin and cholesterol. The evaluation of phytosome was done by particle size and shape, polydispersity index, differential scanning calorimetry and fourier transfer infrared spectroscopy. Further, ex-vivo intestinal permeability study was performed for crude fraction and prepared phytosome to assess the intestinal permeability enhancement. Results: The all standardization parameters showed the results within the standard limits, thus confirming the quality and purity of raw material. The particle size and polydispersity index was found within the acceptable limits. The Differential scanning calorimetry and Fourier transfer infrared spectroscopy studies confirmed that there was no drug interaction with the excipients. The ex-vivo I permeable analysis of the intestines study was found that the phytosome shows enhancement in intestinal permeability than the crude alkaloid fraction. Conclusion: The above results indicated that the prepared alkaloid loaded phytosome shows promising potential in enhancement of intestinal permeability of Tinospora cordifolia.
\end{abstract}

Key words: Phytosomes, Tinospora cordifolia, Permeability, Soya lecithin, Cholesterol.

\section{INTRODUCTION}

In today's world herbal medicines are becoming increasingly popular for their ability to treat a variety of diseases with less harmful effects and better therapeutic value. A new approach to the production of pharmaceutical products which addresses the constraint of the conventional drug delivery system. ${ }^{1}$ Most of the active ingredient in the herbal medicinal products are mainly hydrophilic. Molecules have a minimal effectiveness and are poorly absorbed when taken internally and when used topically. Apart from that due to its bigger molecular size which can't be absorbed via passive diffusion and due to their low lipid solubility limiting its capability to pass throughout the lipid-rich outer membranes of the enterocytes (the cells that line the small intestine) ensuing bad bioavailability of drugs. Therefore, a larger dose is required for dosage administration. ${ }^{2}$ To overcome these problems the novel drug delivery system helps to improve the efficacy and reduces the adverse effects of herbal compounds and herbs. ${ }^{1}$ Phytosomes are newly introduced novel dosage form for improving the bioavailability and therapeutic effect of the herbal drug. ${ }^{1}$ Phytosomes is a nano vesicular drug delivery system in which lipid surrounds and phosphatidylcholine of the lipid bounds to the phytoconstituents of herb extracts. It helps to improve the
Submission Date: 20-07-2020; Revision Date: 15-12-2020; Accepted Date: 22-03-2021

DOI: 10.5530/ijper.55.2.85 Correspondence:

Dr. Kalpana Sabanna Pati KLE College of Pharmacy, Belagavi KLE Academy of Higher Education and Research (KAHER), Belagavi, Karnataka, INDIA. Phone no: +91-9449024899 Email id: kalpatil@yahoo. com

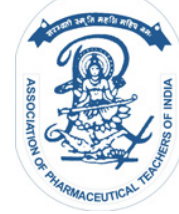

www.ijper.org 
absorption and bioavailability via the pharmacodynamic and pharmacokinetic parameters of herbal extracts. ${ }^{3}$

Tinospora cordifolia (Wild.) Miers, (Guduchi) is a perennial evergreen climber which belongs to the family Menispermaceae. In Ayurveda, it is a plant of considerable medicinal value in the indigenous medicinal system and called Rasayana. Tinospora cordifolia is broadly used folk and traditional Ayurvedic medicine for its, antiinflammatory, antioxidant, anti-diabetic, anti-arthritic and a variety of different medicinal properties. In the treatment of diabetes it is used as highly potent Ayurvedic drug. ${ }^{4}$

The alkaloids from T. cordifolia show poor bioavailability, a high absorption rate and high elimination rate. Hence there is need to design, improve and evaluate an high quality pharmaceutical formulation to enhance its therapeutic effect. ${ }^{5,6}$ So the purpose of this study is to prepare and evaluate the phytosomes from alkaloidal fraction of Tinospora cordifolia to improve its permeability.

\section{MATERIALS AND METHODS}

\section{Materials}

Fresh stem of Tinospora cordifolia was collected from local region of Vengurla, Dist-Sindhudurga, Maharashtra and authenticated by Dr. HarshaHegade, Scientist E, ICMR, Belagavi, Karnataka. Soya lecithin 30\% was purchased from Molychem, Mumbai, India. Cholesterol, BCG reagent, FC Phenol reagent was bought from Himedia laboratories, Mumbai, India. Atropine, Quercetin and Gallic acid was obtained from Sigma Aldrich Chemicals. Ethanol, methanol and dichloromethane was bought from Fisher Scientific, Mumbai.

\section{Methods}

The stem of Tinospora cordifolia was cleaned with tap water and dried under shade. Then dried stem of Tinospora cordifolia was coarsely powdered and kept in the airtight neatly labelled jar till the further use.

\section{Pharmacognostic Studies}

\section{Microscopic Study 7,8}

Powder microscopy was done by using Trinocular microscope. For powder microscopy dried stem powder was used.

\section{Physicochemical Studies ${ }^{8,9}$}

Physicochemical parameters were calculated according to $\mathrm{WHO}$ guidelines.

\section{Extraction of Plant material}

Dried stem powder was subjected to cold maceration with $70 \% \mathrm{v} / \mathrm{v}$ ethanol with occasional shaking. Extract was filtered and filtrate was collected in clean glass container. The marc was further expose to soxhlation with ethanol of $95 \%$ at $40^{\circ} \mathrm{C}$. Filtering of both maceration and soxhelation was combined and optimized at $40^{\circ} \mathrm{C}$ under reduced pressure using a rotary evaporator (IKA RV 10). Obtained extract was dried and stored in air tight container..$^{10}$

\section{Preliminary Phytochemical screening ${ }^{9}$}

The extract of herbal drugs was subjected to phytochemical tests to assess the qualitative chemical composition of the extract by standard method. A phytochemical test was carried out to identify the chemical constituents present in Tinospora cordifolia stem extract.

\section{Determination of Total Alkaloid Content}

Total Alkaloid Content ${ }^{11}$ of $T$. cordifolia stem extract was determined by spectrophotometric method. This method is based on the reaction between alkaloid and bromocresol green (BCG). 1 $\mathrm{mg}$ of stem extract was dissolved in $2 \mathrm{~N} \mathrm{HCl}$ and filtered. From the above solution $1 \mathrm{ml}$ of solution was transferred in separating funnel and then $5 \mathrm{ml}$ of BCG solution and $5 \mathrm{ml}$ of phosphate buffer ( $\mathrm{pH}$ 7.4) were added in it. Shake the mixture and formed complex extracted with 1,2,3 and $4 \mathrm{ml}$ chloroform respectively with vigrous shaking. Then extract was collected in $10 \mathrm{ml}$ volumetric flask and make up the volume with chloroform. Absorbance was measured at $470 \mathrm{~nm}$ against the same mixture but without stem extract as a blank.

A set of standard atropine reference solution (20,40, 60,80 and $100 \mathrm{mcg} / \mathrm{ml}$ ) was prepared in same manner as above. The calibration curve is depicted in Figure 1. The total alkaloid content of the extract was expressed as $\mathrm{mg}$ of $\mathrm{AE} / \mathrm{g}$.

\section{Determination of Phenolic Total Content}

Total Phenolic Content ${ }^{11,12}$ of T. cordifolia stem extract was determined by Folin-Ciocalteu colorimetric assay. $1 \mathrm{ml}$ of stem extract and $9 \mathrm{ml}$ of dist. water was taken in $25 \mathrm{ml}$ volumetric flask. Add $1 \mathrm{ml}$ FC Phenol reagent and shake well. Then, After $5 \mathrm{~min}$, add $10 \mathrm{ml}$ of $7 \% \mathrm{Na}_{2} \mathrm{CO}_{3}$ and make upto $25 \mathrm{ml}$ with dist. water and incubated for $1 \mathrm{hr}$ at room temperature. Absorbance was measured at 765 $\mathrm{nm}$ against the same mixture but without stem extract as a blank. A set of standard Gallic acid reference solution 
$(20,40,60,80$ and $100 \mathrm{mcg} / \mathrm{ml})$ was prepared in same manner as above. Calibration curve for standard gallic acid is depicted in Figure 2. The total phenolic content of the extract was expressed as $\mathrm{mg}$ of $\mathrm{GAE} / \mathrm{g}$.

\section{Determination of Total Flavonoid Content}

Total flavonoid content ${ }^{11,12}$ of $T$. cordifolia stem extract was determined by aluminium chloride colorimetric assay. $1 \mathrm{ml}$ stem extract and $4 \mathrm{ml}$ dist. water was taken in $10 \mathrm{ml}$ volumetric flask. Added $0.30 \mathrm{ml}$ of $5 \%$ sodium nitrate in the above volumetric flask and incubated for $5 \mathrm{~min}$ at room temperature. After incubation add 0.3 $\mathrm{ml}$ of $10 \%$ aluminium chloride and again incubated for $5 \mathrm{~min}$ at room temperature. Then add $2 \mathrm{ml}$ of $1 \mathrm{M}$ sodium hydroxide and diluted upto $10 \mathrm{ml}$ with distilled water and incubated for $15 \mathrm{~min}$ at room temperature. The absorbance was measured at $510 \mathrm{~nm}$ against the same mixture but without stem extract as a blank.

A set of standard Quercetin reference solution (20, 40, 60,80 and $100 \mathrm{mcg} / \mathrm{ml}$ ) was prepared in same manner as above. Calibration curve for standard quercetin is depicted in Figure 3. The total flavonoid content of the extract was expressed as $\mathrm{mg}$ of $\mathrm{QE} / \mathrm{g}$.

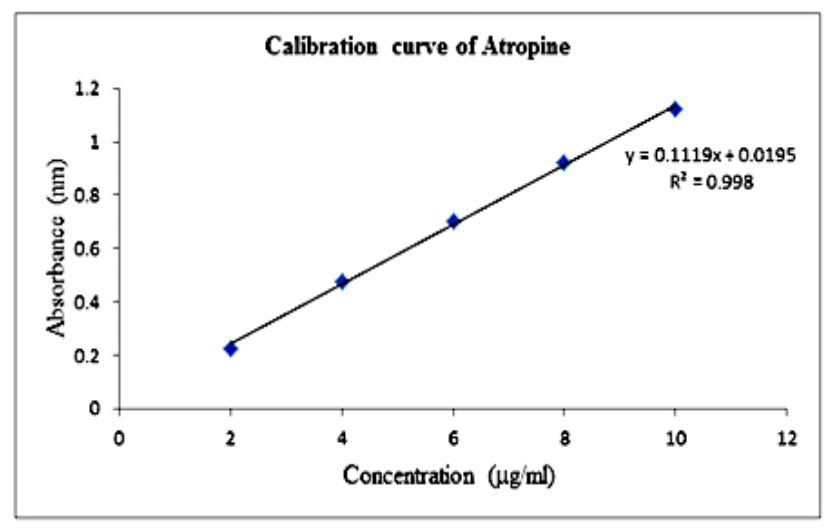

Figure 1: Calibration curve for standard atropine for determination of Total alkaloid content.

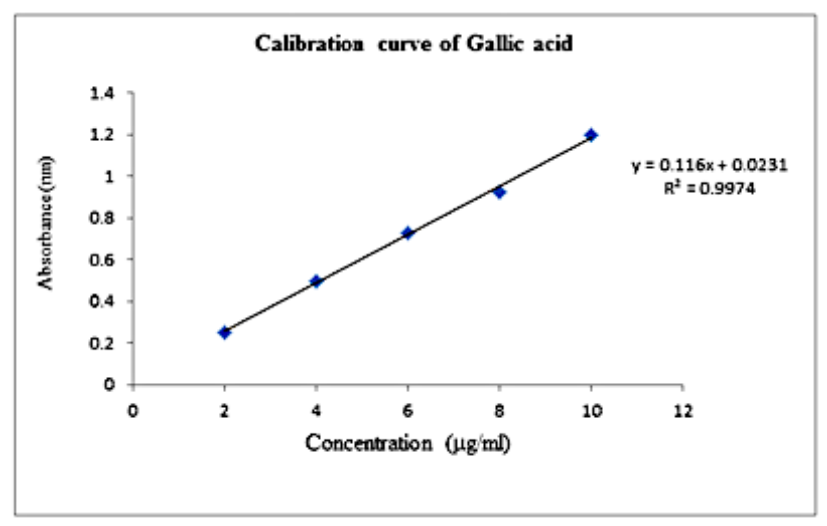

Figure 2: Calibration curve for standard gallic acid for Determination of Total phenolic content.

\section{Fractionation of Tinospora cordifolia Stem Extract}

Fractionation of Tinospora cordifolia stem extract was carried out as per Cos et al. method. ${ }^{13}$ The stem extract was dispersed in 5\% w/v citric acid and washed with dichloromethane. Dichloromethane and aqueous layer were separated. Separated dichloromethane layer was partitioned with 90\% v/v methanol and petroleum ether (1:1) to get fraction 1 and fraction 2. Aqueous layer was concentrated to half and $\mathrm{pH}$ adjusted to 9.0 with 10\% ammonium hydroxide. Aqueous layer was washed with dichloromethane, which gives fraction 3 and fraction 4. Fraction containing alkaloids was used for further studies.

\section{Preparation of Phytosomes}

Phytosomes was prepared ${ }^{14,15}$ by using thin layer hydration method with different molar ratio of drug, $30 \%$ Soya lecithin and cholesterol. Accurately weighed amount of soya lecithin and cholesterol was dissolved in dichloromethane, while drug was dissolved in methanol. The above mixture was taken in round bottom flask and evaporated in rotary evaporator at $40^{\circ} \mathrm{C}$ at $180 \mathrm{r} /$ min and vacuumed until evaporate the all solvent and thin layer was obtained to RBF. The flask was stored in refrigerator upto $24 \mathrm{hrs}$. The film was hydrated with mixture of ethanol and water (1:1) in rotary evaporator at $40^{\circ} \mathrm{C}$ for $1 \mathrm{hr}$. Once the phytosomal suspension was formed the sonication was done for $30 \mathrm{~min}$ to reduce the particle size. Total four phytosomal formulations (Table 4) of alkaloid content from Tinospora cordifolia were prepared using soya lecithin and cholesterol.

\section{Evaluation of Phytosomes ${ }^{16-18}$ \\ a) Determination of particle size}

Vesicles particle size and polydispersity index (PDI) analysis was performed using Nanotrac instrument. 1 $\mathrm{ml}$ phytosome suspension was diluted upto $10 \mathrm{ml}$ with

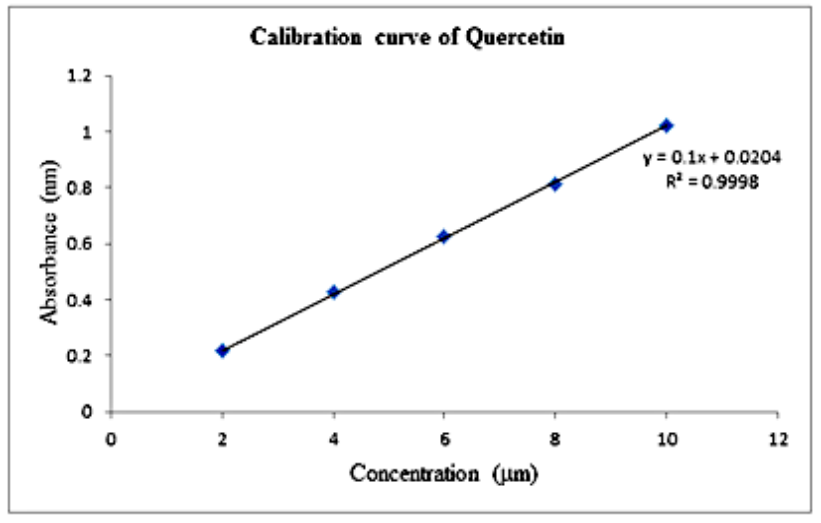

Figure 3: Calibration curve for standard quercetin for determination of Total flavonoid content. 
Millipore water and particle size was determined. Particle size and polydispersity index of of the phytosome formulation FS4 is depicted in Figure 4.

\section{b) Vesicles Morphology}

Shape and Surface morphology of phytosomes were studied using Trinocular microscopy and scanning electron microscopy (SEM) (Figure 5).

\section{c) Differential scanning calorimetry (DSC)}

Differential scanning calorimetry (DSC) analysis was performed on a DSC60 detector. Approximately $2 \mathrm{mg}$ of pure alkaloid fraction, physical mixture of fraction with excipients and phytosomes was weighed in an aluminium pan and sealed hermetically. DSC scan was recordedfrom $30^{\circ} \mathrm{C}$ to $300^{\circ} \mathrm{C}$ at a heating rate of $10^{\circ} \mathrm{C} /$

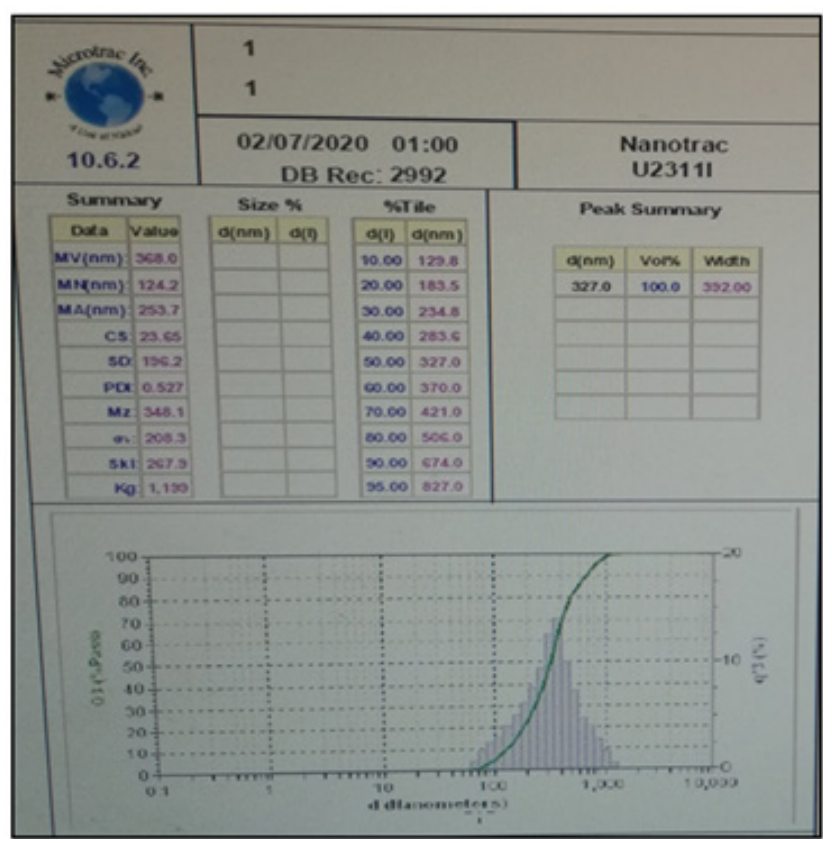

Figure 4: Particle size and PDI of Optimized phytosome formulation FS4.
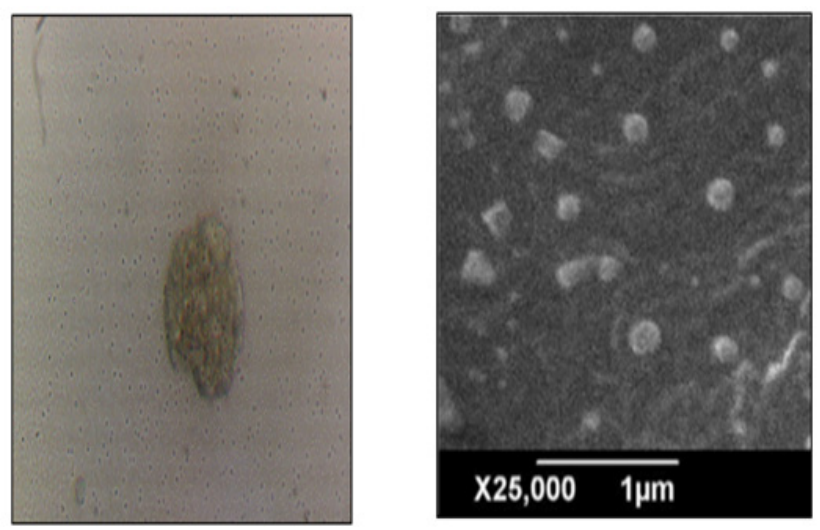

Figure 5: Vesicles Morphology of Phytosome formulation.

min under a nitrogen purge. Empty pan was considered as reference (Figure 6).

\section{d) FT-IR Spectroscopy}

Fourier Transform Infrared (FT-IR) technique is used to study the physical and chemical interaction between drug and excipients. FT-IR spectrum of pure alkaloid fraction, physical mixture of fraction with excipients and phytosomes was carried out to check the compatibility of drug after combining with the excipients by potassium bromide method (Figure 7).

\section{Ex-vivo Intestinal Permeability Study ${ }^{19-21}$}

Ex-vivo permeation study was performed by using noneverted gut sac method using chicken ileum, collected from nearby slaughter house. The separated two small segments were washed at room temperature six times with Krebs Ringer's solution together with continuous aeration. After washing, two segments of the ileum were filled with phytosomal suspension as well as aqueous raw alkaloid fraction solution. Such segments were tightened at both ends and placed under continuous bubbled with atmosphere air in a beaker containing $50 \mathrm{ml}$ of Krebs Ringer's solution. In order tomaintain the temperature at $37 \pm 0.5^{\circ} \mathrm{C}$, the gut sac bath is enclosed by an outer water jacket. After $1 \mathrm{hr}$ the all drug solution was withdrawn and release amount of alkaloid from Tinospora cordifolia was determined by estimation of total alkaloid content.

\section{RESULTS AND DISCUSSION \\ Microscopic Study \\ Powder Microscopy}

The powdered material of Tinospora cordifolia stem was creamish brown in color, odorless and slightly bitter in taste. Microscopy study of powder showed the presence

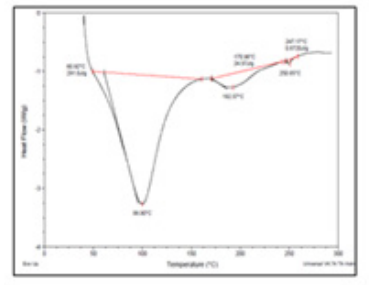

A

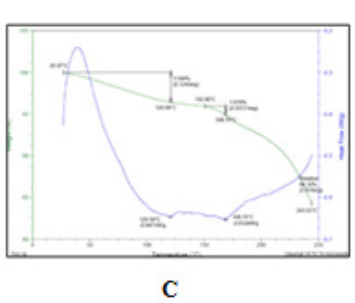

Figure 6: DSC of a) Fraction, b) Physical mixture, c) Phytosome. 
of fibers which are lignified and long in shape. Tracheids with bordered pits and horizontal perforations. Xylem vessels cylindrical and bear bordered pits (Figure 8).

\section{Physicochemical study}

The physico-chemical investigation tests were performed to analyze the quality and purity of Tinospora cordifolia. Ash value is useful in determining the authenticity and purity of the plant material. The total ash, acid insoluble and water soluble ash value for Tinospora cordifolia was found in range of $10 \pm 0.6,2 \pm 0.05$ and $7 \pm 0.25$ respectively. The water soluble extractive value is higher than alcohol soluble extractive in T. cordifolia. The samples of alcohol soluble and water soluble extractive values were found within the range of $7 \pm 0.5$ and $19 \pm 0.25$ respectively. The major factor responsible for the deterioration of the samples is moisture. Low moisture is always desirable for greater stability of drugs. The loss on drying in Tinospora cordifolia plant were found within the range of $1.76 \pm 0.04$ (Table 1).

\section{Preliminary phytochemical screening}

The phytochemical screening of extract shows the presence of alkaloids, carbohydrates, terpenoids, tannins, steroids, flavonoids and phenols in the $T$. cordifolia extract. Saponins are absent in the extract (Table 2).

\section{Determination of total alkaloid, phenol and flavonoid content}

The total alkaloid, phenolic and flavonoid content was found to be $6.1 \pm 0.001 \mathrm{mgAE} / \mathrm{g}, 5.4 \pm 0.05 \mathrm{mgGAE} / \mathrm{g}$, $3.6 \pm 0.02 \mathrm{mg}$ QE/g respectively in Tinospora cordifolia stem extract. Table 3 summarizes the data for determination of total alkaloid, phenolic and flavonoid content.

\begin{tabular}{|c|c|c|c|}
\multicolumn{3}{|c|}{ Table 1: Physiochemical investigation of Tinospora } \\
cordifolia. \\
Sr. \\
No & $\begin{array}{c}\text { Physico- } \\
\text { chemical } \\
\text { Parameters } \\
(\% w / w)\end{array}$ & $\begin{array}{c}\text { Results for } \\
\text { Tinospora } \\
\text { cordifolia } \\
(\% w / w)\end{array}$ & $\begin{array}{c}\text { Standard Value } \\
(\% \text { w/w })\end{array}$ \\
\hline 1. & Total ash & $10 \pm 0.6$ & NMT $10 \%$ \\
\hline 2. & $\begin{array}{c}\text { Acid Insoluble } \\
\text { ash }\end{array}$ & $2 \pm 0.05$ & NMT $3 \%$ \\
\hline 3. & $\begin{array}{c}\text { Water soluble } \\
\text { ash }\end{array}$ & $7 \pm 0.25$ & NMT $20 \%$ \\
\hline 4. & $\begin{array}{c}\text { Alcohol Soluble } \\
\text { Extractive value }\end{array}$ & $7 \pm 0.5$ & NLT $1.5 \%$ \\
\hline 5. & $\begin{array}{c}\text { Water Soluble } \\
\text { Extractive value }\end{array}$ & $19 \pm 0.25$ & NLT $9 \%$ \\
\hline 6. & Loss on drying & $1.76 \pm 0.04$ & NMT $10 \%$ \\
\hline
\end{tabular}

Results are presented as the mean $\pm \mathrm{SD},(n=3)$

\begin{tabular}{|c|c|c|c|}
\hline \multicolumn{2}{|c|}{ Phytochemical Test } & Observation & T. cordifolia Extract \\
\hline \multirow{4}{*}{ Alkaloid } & Mayer's Test & Gives ppt & + \\
\hline & Dragendorff's Test & Orange-Brown ppt & + \\
\hline & Wagner's Test & Reddish-Brown ppt & + \\
\hline & Hager's Test & Yellow ppt & + \\
\hline Carbohydrates & Molisch's Test & $\begin{array}{l}\text { violet ring formation at } \\
\text { intersection of two liquids }\end{array}$ & 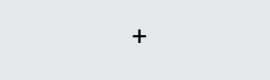 \\
\hline \multirow{2}{*}{ Flavonoids } & Shinoda Test & $\begin{array}{l}\text { Orange, Pink, Red to Purple } \\
\text { colour }\end{array}$ & + \\
\hline & $\mathrm{NaOH}+$ Conc. $\mathrm{H}_{2} \mathrm{SO}_{4}$ & $\begin{array}{c}\mathrm{NaOH}-\text { Colouration } \mathrm{H}_{2} \mathrm{SO}_{4}- \\
\text { Decolouration }\end{array}$ & + \\
\hline Tannins & Lead Acetate Test & Yellow ppt & + \\
\hline Terpenoids & Salkowski Test & $\begin{array}{c}\text { Chloroform layer - Red } \\
\text { colour } \\
\text { Acid layer - Greenish yellow } \\
\text { fluorescence }\end{array}$ & + \\
\hline Steroids & LibbermannBurchard Test & Red, Blue to Green colour & + \\
\hline Polyphenols & $10 \% \mathrm{FeCl}_{3}$ Test & Blue / Green colour & + \\
\hline Saponins & Foam Test & Foam formation & - \\
\hline
\end{tabular}




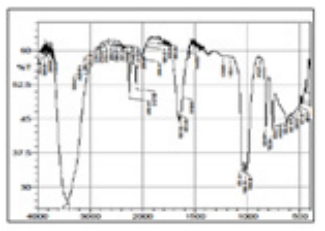

A

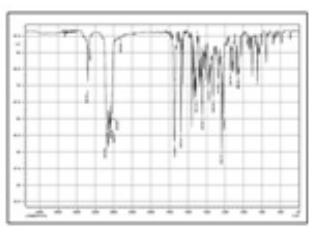

C

Figure 7: FTIR of a) fraction, b) Physical mixture, c) Phytosome.

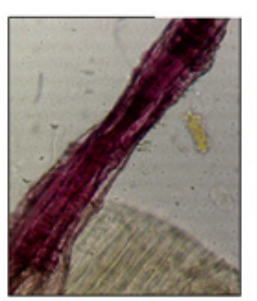

Fibers
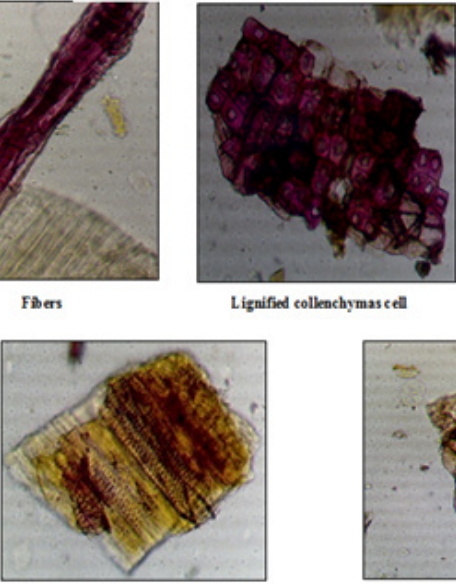

Lignified collenchymas cell

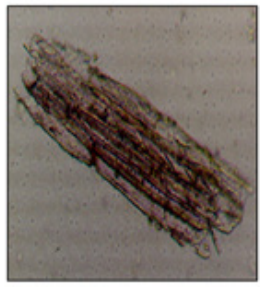

Irached

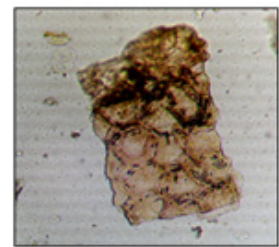

Figure 8: Photographs of powder microscopy of Tinospora cordifolia stem.

\section{Table 3: Data for determination of total alkaloid, phenolic and flavonoid content.}

\begin{tabular}{|c|c|c|c|}
\hline Sr. & Plant Name & Parameters & Results \\
\cline { 1 - 1 } 1. & \multirow{2}{*}{$\begin{array}{c}\text { Tinospora } \\
\text { cordifolia }\end{array}$} & $\begin{array}{c}\text { Total alkaloid content } \\
\text { (mg AE/g dry extract) }\end{array}$ & $6.1 \pm 0.001$ \\
\cline { 1 - 1 } 2. & $\begin{array}{c}\text { Total phenolic content } \\
\text { (mg GAE/g dry } \\
\text { extract) }\end{array}$ & $5.4 \pm 0.05$ \\
\cline { 1 - 1 } 3. & $\begin{array}{c}\text { Total flavonoids } \\
\text { (mg QE/g dry extract) }\end{array}$ & $3.6 \pm 0.02$ \\
\hline
\end{tabular}

Results are presented as the mean $\pm \mathrm{SD},(n=3)$

\section{Evaluation of Phytosomes}

\section{Particle Size}

The particle size and polydispersity index (PDI) of phytosome was measured by Nanotrac Particle Size Analyzer. Particle size data and polydispersity index for prepared phytosome formulations FS1 to FS2 was listed in Table 5. Smaller particle size indicates better drug permeation and PDI indicates uniform size distribution of particles. The particle size of formulation FS 4 is 368 \pm 0.12 and PDI was 0.5. So, Formulation FS 4 shows smaller particle size and PDI range which is used as optimized formulation for further study.

\section{Vesicles morphology}

Shapeand surfacemorphologyof phytosomeformulation FS 4 was studied using Trinocular microscope and Scanning electron microscopy. Trinocular microscopy and SEM photographs of formulation FS 4 was shown in Figure 5. The phytosome formulation FS 4 was found to be smooth and spherical in shape.

\section{Differential Scanning Colorimetry (DSC)}

The obtained thermograms of pure fraction, physical mixture and phytosome formulation by Differential scanning Colorimetry (DSC) were Figure 6. The fraction in physical mixture showed the melting point within the range with no additional shift in endothermic peak which indicated that drug is compatible with other ingredient. The pure fraction exhibited sharp endothermic peak at $99.90^{\circ} \mathrm{C}$.

\section{FT-IR Spectroscopy}

FT-IR spectroscopy was performed to study the compatibility of pure fraction and physical mixture of fraction with soya lecithin and phytosome formulation respectively. From the FT-IR spectra observed that characteristic peak of drug was present in the combination also. The reported peak frequencies were shown in Table 6. The functional groups are lies within the limit and there is no interaction between drug and excipients.

\section{Ex-vivo intestinal permeability study}

The Ex-vivo permeation study was performed with the help of everted gut sac method using chicken ileum. This study shows the linkage between drug absorption and drug permeation. Result of the study shows that the phytosome formulation (FS4) was more permeated within $1 \mathrm{hr}$ because of incorporation of fraction inside the lipid matrix while permeation of fraction (F3) is less. The phytosome formulation (FS4) was found to be 1.85 times more permeable than the pure fraction (F3) (Table 7). The formulated phytosomes shows more potency in enhancement of drug permeability as compared to pure fraction of alkaloid from Tinospora cordifolia. 


\begin{tabular}{|c|c|c|c|c|c|c|c|c|c|}
\hline$\frac{\circ}{\sum}$ & 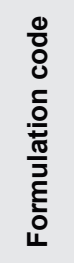 & 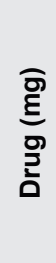 & 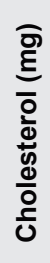 & 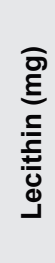 & 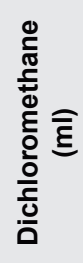 & 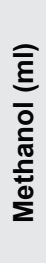 & 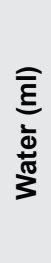 & 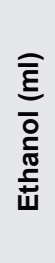 & 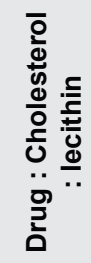 \\
\hline 1. & FS1 & 10 & 15 & 10 & 10 & 5 & 10 & 10 & $1: 1.5: 1$ \\
\hline 2. & FS2 & 10 & 15 & 20 & 10 & 5 & 10 & 10 & $1: 1.5: 2$ \\
\hline 3. & FS3 & 10 & 15 & 30 & 10 & 5 & 10 & 10 & $1: 1.5: 3$ \\
\hline 4. & FS4 & 10 & 15 & 40 & 10 & 5 & 10 & 10 & $1: 1.5: 4$ \\
\hline
\end{tabular}

\section{Table 5: Particle size and PDI of vesicles.}

\begin{tabular}{|c|c|c|c|}
\hline Sr.No & $\begin{array}{c}\text { Formulation } \\
\text { Code }\end{array}$ & $\begin{array}{c}\text { Particle Size } \\
(\mathbf{n m})\end{array}$ & PDI \\
\hline 1. & FS 1 & $628 \pm 76$ & 0.7 \\
\hline 2. & FS 2 & $587 \pm 0.85$ & 0.9 \\
\hline 3. & FS 3 & $554 \pm 0.62$ & 0.7 \\
\hline 4. & FS 4 & $368 \pm 0.12$ & 0.5 \\
\hline
\end{tabular}

\begin{tabular}{|c|c|c|c|}
\hline \multirow[b]{2}{*}{$\begin{array}{c}\text { Functional } \\
\text { Group }\end{array}$} & \multicolumn{3}{|c|}{ Observed Frequencies } \\
\hline & $\begin{array}{c}\text { Pure } \\
\text { Fraction }\end{array}$ & $\begin{array}{c}\text { Fraction + } \\
\text { excipients } \\
\text { (Physical } \\
\text { Mixture) }\end{array}$ & $\begin{array}{l}\text { Phytosome } \\
\text { formulation }\end{array}$ \\
\hline $\mathrm{N}-\mathrm{H}$ Strech & 3316 & 3317 & 3227 \\
\hline C-O Stretch & 1141 & 1714 & 1514.72 \\
\hline C-H Stretch & 1482.95 & 2922 & 2995.68 \\
\hline C-C Stretch & 1473 & 1437 & 1641.05 \\
\hline $\mathrm{C}=\mathrm{C}$ Stretch & 1514.22 & 1514 & 1516.12 \\
\hline
\end{tabular}

Table 7: Data for Ex-vivo intestinal permeability Study.

\begin{tabular}{|c|c|c|}
\hline Sr. No & Parameter & Result \\
\hline 1. & $\begin{array}{c}\text { Alkaloid content of pure fraction } \\
\text { (After permeation through ileum) }\end{array}$ & $6.88 \pm 0.69$ \\
\hline 2. & $\begin{array}{c}\text { Alkaloid content of formulated } \\
\text { phytosomes (after permeation } \\
\text { through ileum) }\end{array}$ & $12.77 \pm 0.50$ \\
\hline
\end{tabular}

\section{CONCLUSION}

The above study conclude that alkaloid loaded phytosomes from stem of Tinospora cordifolia has better physical characteristics than crude alkaloid fraction. Ex-vivo intestinal permeability study revealed that the phytosome formulation shows more potency in enhancement of permeability of alkaloids incorporated in it than the crude alkaloid fraction.

\section{ACKNOWLEDGEMENT}

Authors are thankful to the Principal KLE College of Pharmacy, Belagavi, for his support and encouragement to carry out the research work.

\section{CONFLICT OF INTEREST}

The authors declare no conflict of interest.

\section{ABBREVIATIONS}

BCG: Bromocresol Green; PDI: Polydispersity Index; SEM: Scanning Electron Microscopy; DSC: Differential Scanning Calorimetry; FT-IR: Fourier Transform Infrared.

\section{REFERENCES}

1. Sravanthi M, Shiva KJ. Phytosomes: A novel drug delivery for herbal extracts. International Journal of Pharmaceutical Sciences Research. 2013;4(3):94959.

2. Patel A, Tanwar YS, Suman R, Patel P. Phytosomes: Phytolipid drug delivery system for improving bioavailability of herbal drug. Journal of Pharmaceutical Science and Bioscientific Research. 2013;3(2):51-2.

3. Jalalpure SS, Kurangi BK. A Textbook of Herbal Drug Technology. Vallabh Prakashan, Delhi. 2020.

4. Choudhary N, Siddiqui MB, Khatoon S. Pharmacognostical evaluation of Tinospora cordifolia (Wild.) Miers and identification of biomarkers. Indian Journal of Traditional Knowledge. 2014;13(3):543-50.

5. Khanal P, Patil BM, Mandar BK, Dey YN, Duyu T. Network pharmacologybased assessment to elucidate the molecular mechanism of anti-diabetic action of Tinospora cordifolia. Clin Phytosci. 2019;5(1):35. 
6. Khanal P, Mandar BK, Patil BM, Hullatti KK. In silico antidiabetic screening of Borapetoside C, Cordifolioside A and Magnoflorine. Indian Journal of Pharmaceutical Sciences. 2019;81(3):550-5.

7. Nasreen S, Radha R, Jayashree N, Selvaraj B, Rajendran A. Assessment of quality of Tinospora cordifolia (willd.)Miers. (menispermaceae): Pharmacognostical and phyto physicochemical profile. Pharmacie Globale International Journal of Comprehensive Pharmacy. 2010;1(5):1-4.

8. Quality control methods for herbal materials. WHO, Geneva. 2011.

9. Khandelwal KR. Practical Pharmacognosy: Techniques and Experiments, Nirali Prakashan, Pune. 2003.

10. Kumar V, Singh S, Singh A, Dixit AK, Srivastava B, Sidhu GK, et al. Phytochemical, Antioxidant, Antimicrobial, and Protein Binding Qualities of Hydro-ethanolic Extract of Tinospora cordifolia. Journal of Biologically Active Products from Nature. 2018;8(3):1-10.

11. Tambe VD, Bhambar RS. Estimation of Total Phenol, Tannin, Alkaloid and Flavonoid In Hibiscus tiliaceus Linn. Wood Extracts. Research and reviews: Journal of Pharmacognosy and Phytochemistry. 2014;2(4):41-7.

12. Borkataky M, Kakoty BB, Saikia L. Influence of total phenolic and total flavonoidcontent on the DPPH radical scavenging activity of Ecliptaalba (L.) Hassk. International Journal of Pharmacy and Pharmaceutical Sciences. 2013;5(1):224-327.

13. Cos P, Vlietinck AJ, Berghe DV, Maes L. Anti-infective potential of natural products: How to develop a stronger in vitro 'proof-of-concept'. Journal of Ethnopharmacology. 2006;106(3):290-302.
14. Hooresfand Z, Ghanbarzadeh S, Hamishekhar H. Preparation and Characterization of Rutin-loaded Nanophytosomes. Pharmaceutical Sciences. 2015;21(1):145-51.

15. Anwar E, Farhana N. Formulation and evaluation of phytosomes- loaded maltodextrin-gum Arabic microspere system for delivery of Camellia sinensis extract. Journal of Young Pharmacist. 2018;10(2):s56-62.

16. Rasaie S, Ghanbarzadeh S, Mohammadi M, Hamishekhar H. Nanophytosomes of Quercetine: A promising formulation for fortification of food Products with antioxidants. Pharmaceutical Sciences. 2014;20(3):96101.

17. Mazumdar A, Dwivedi A, Preez J, Plessis J. In vitro wound healing and cytotoxic effects of sinigrin-phytosome complex. International Journal of Pharmaceutics. 2016;498(1-2):283-93.

18. Telange DR, Patil AT, Pethe AM, Fegade H, Anand S, Dave VS. Formulation and characterization of an apigenin-phospholipid phytosome (APLC) for improved solubility, in vivo bioavailability and antioxidant potential. European Journal of Pharmaceutical Sciences. 2016. http://dx.doi.org/10.1016/j. ejps.2016.12.009

19. Jain PK, Khurana N, Pounikar Y, Gajbhiye A, Kharya MD. Enhancement of absorption and hepatoprotective potential through Soya-phosphatidylcholineandrographolide vesicular system. Journal of Liposome Research. 2013;23(2):110-8.

20. Dixit P, Jain DK, Dumbwani J. Standardization of an ex vivo method for determination ofintestinal permeability of drugs using everted rat intestine apparatus. Journal of Pharmacological and Toxicological Methods. 2012;65(1):13-7.

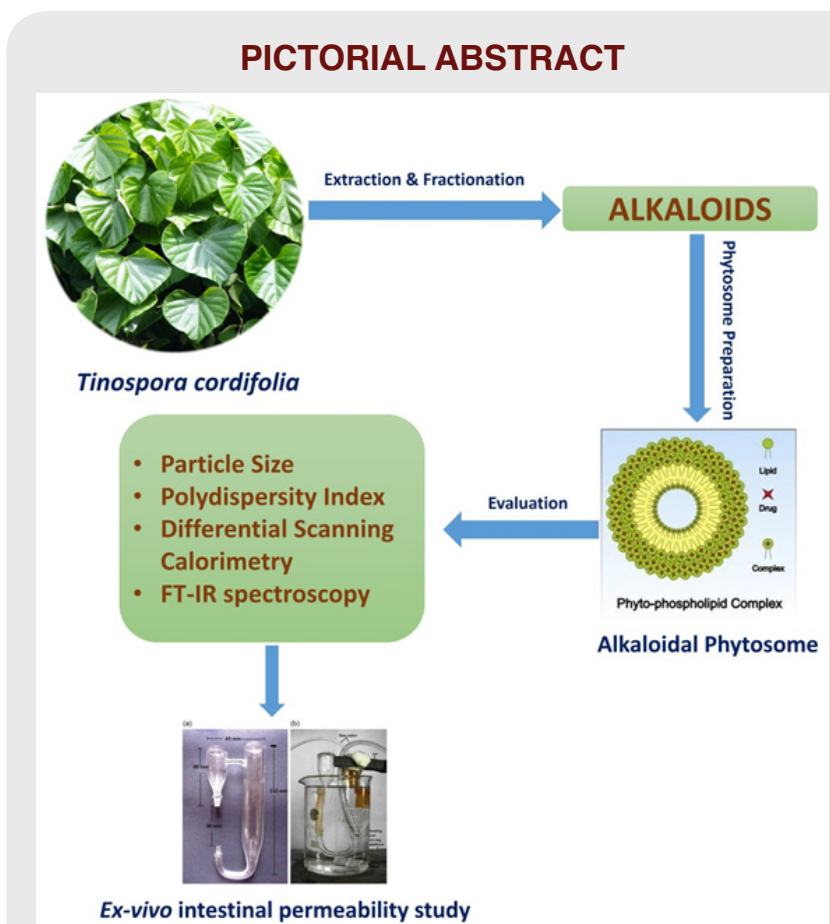

Ex-vivo intestinal permeability study

\section{SUMMARY}

Phytosomes are newly introduced novel dosage form for improving the bioavailability and therapeutic effect of the herbal drug. In the present study preparation and evaluation of alkaloid loaded phytosome from Tinospora cordifolia was carried out. The hydroalcoholic extracts of $T$. cordifolia were screened for total content of phenols, flavonoids and alkaloids. A total four Phytosome formulations were prepared by using thin film hydration method with different ratio of soya lecithin and cholesterol. Further evaluation of phytosome was carried out. The ex-vivo intestinal permeability study was performed for crude fraction and prepared phytosome to assess the intestinal permeability enhancement. The all standardization parameters showed the results within the standard limits, thus confirming the quality and purity of raw material. The particle size and polydispersity index was found within the acceptable limits. In ex-vivo permeability analysis of the intestines study was found that the phytosome shows enhancement in intestinal permeability than the crude alkaloid fraction. The above results indicated that the prepared alkaloid loaded phytosome shows promising potential in enhancement of intestinal permeability of Tinospora cordifolia. 


\section{About Authors}

Aishwarya Laxman Thakur, is Post graduate student, Department of Pharmacognosy, College of Pharmacy,

Kalpana Patil, is presently working as a Professor \& HoD, Department of Pharmacognosy, College of Pharmacy, Belagavi. She has published over 70 scientific papers in national and international journals and presented 80 papers at national and international conferences. She has successfully guided $47 \mathrm{M}$. Pharm. and 3 Ph.D. students.

Cite this article: Thakur AL, Patil KS. Formulation of Alkaloid Loaded Phytosomes from Tinospora cordifolia and ex-vivo Intestinal Permeability Study. Indian J of Pharmaceutical Education and Research. 2021;55(2):474-82. 